\title{
Incidence of human rabies and characterization of rabies virus nucleoprotein gene in dogs in Fujian Province, Southeast China, 2002-2012
}

Jian-Ming Zhang ${ }^{1,2}$, Zhi-Shan Zhang ${ }^{1 *}$, Yan-Qin Deng ${ }^{3,4}$, Shou-Li Wu ${ }^{2,3,4}$, Wei Wang ${ }^{5,6,7^{*}}$ (D) and Yan-Sheng Yan ${ }^{2,3,4}$

\begin{abstract}
Background: Rabies is a global fatal infectious viral disease that is characterized by a high mortality after onset of clinical symptoms. Recently, there has been an increase in the incidence of rabies in China. The aim of this study was to investigate the incidence of human rabies and characterize the rabies virus nucleoprotein gene in dogs sampled from Fujian Province, Southeast China from 2002 to 2012.
\end{abstract}

Methods: Data pertaining to human rabies cases in Fujian Province during the period from 2002 through 2012 were collected, and the epidemiological profiles were described. The saliva and brain specimens were collected from dogs in Quanzhou, Longyan and Sanming cities of the province, and the rabies virus antigen was determined in the canine saliva specimens using an ELISA assay. Rabies virus RNA was extracted from canine brain specimens, and rabies virus nucleoprotein gene was amplified using a nested RT-PCR assay, followed by sequencing and genotyping.

Results: A total of 226 human rabies cases were reported in Fujian Province from 2002 to 2012, in which 197 cases were detected in three cities of Quanzhou, Longyan and Sanming. ELISA assay revealed positive rabies virus antigen in six of eight rabid dogs and 165 of 3492 seemingly healthy dogs. The full-length gene fragment of the rabies virus nucleoprotein gene was amplified from the brain specimens of seven rabid dogs and 12 seemingly healthy dogs. Sequence alignment and phylogenetic analysis revealed that these 19 rabies virus nucleoprotein genes all belonged to genotype I, and were classified into three genetic groups. Sequencing analysis showed a $99.7 \%$ to $100 \%$ intra-group and an $86.4 \%$ to $89.3 \%$ inter-group homology.

Conclusions: This study is the first description pertaining to the epidemiological characteristics of human rabies cases and characterization of the rabies virus nucleoprotein gene in dogs in Fujian Province, Southeast China. Our findings may provide valuable knowledge for the development of strategies targeting the prevention and control of rabies.

Keywords: Rabies, Epidemiological features, Rabies virus, Nucleoprotein gene, Fujian Province

\section{Background}

Rabies is a fatal disease that is mainly transmitted by the bites of dogs. Globally, rabies is responsible for approximately 55,000 deaths each year [1]. In China, a total of 108,412 human rabies cases have been reported between

\footnotetext{
* Correspondence: 554882707@qq.com; wangwei@jipd.com

'Clinical Laboratory, The Affiliated Quanzhou First Hospital of Fujian Medical University, No. 248 East Street, Quanzhou City, Fujian Province 362002, China ${ }^{5}$ Jiangsu Institute of Parasitic Diseases, No. 117 Yangxiang, Meiyuan, Wuxi City, Jiangsu Province 214064, China

Full list of author information is available at the end of the article
}

1950 and 2004, yielding to India as a country with the second highest number of rabies victims [2].

During the past decade, there has been a sharp increase in the incidence of human rabies in Fujian Province, Southeast China [3-5]. This trend reflects a rapid increase in the number of domestic dogs that lack effective canine vaccination and control measures, especially in the countryside [6]. However, the incidence of human rabies and the genotypes of dog rabies viruses remain unknown in Southeast China until now. This study aimed to investigate the 
incidence of human rabies and characterize dog rabies virus in Fujian province, Southeast China from 2002 to 2012 .

\section{Methods}

\section{Ethical statement}

This study was approved by the Ethical Review Committee of Fujian Provincial Center for Disease Control and Prevention (CDC) (permission number: FJCDC-001207), and the study protocol was reviewed by the Institutional Review Board of Fujian CDC. All animal experiments were performed according to the Guidelines for the Care and Use of Laboratory Animals, and written informed consent was obtained from all human rabies cases described in this study.

\section{Collection of human rabies cases}

The data pertaining to human rabies cases were captured from the annual reports of Fujian CDC (Fuzhou, China) during the period from 2002 through 2012, and the epidemiological profile of the cases was described.

\section{Canine samples}

Dogs were sampled from Quanzhou, Longyan and Sanming cities, which had the highest incidence of human rabies in Fujian Province, Southeast China (Fig. 1). Table 1 shows the geographical origin and date of collection of all canine samples for the amplification of the rabies viral nucleoprotein $(N)$ gene.

\section{Detection of rabies virus antigen in dog saliva}

Saliva specimens were collected from both rabid and seemingly healthy dogs housed in nine randomly selected villages from each city. For saliva sampling, each dog was housed in a cage, and sterile Q-tips/ cotton balls were placed in mouth until Q-tips/cotton balls were thoroughly soaked by the saliva. Saliva specimens were kept in cold storage, immediately transferred to laboratory, pretreated by centrifugation and stored at $-20{ }^{\circ} \mathrm{C}$ for subsequent tests. The rabies virus antigen was detected in saliva specimens using an enzyme-linked immunosorbent assay (ELISA) kit (Wuhan Institute of Biological Products; Wuhan, China) following the manufacturer's protocol. In this study, a rabid dog was defined as a dog that actively attacked humans and animals and presented sympathetic hyperfunction, which showed manifestations of salivation, manic agitation and disturbance of consciousness.

\section{Amplification, cloning, sequencing and phylogenetic analysis of $N$ gene in dog brain}

A total of eight rabid dogs were sacrificed, and 81 seeming healthy (asymptomatic) dogs were euthanized.
Canine brain tissues were collected and stored at $-70{ }^{\circ} \mathrm{C}$ for the subsequent experiments. Total RNA was extracted from canine brain specimens using a Trizol reagent (Invitrogen; Carlsbad, CA, USA) according to the manufacturer's instructions. $N$ gene was amplified from the brain specimens using a nested reverse transcription polymerase chain reaction (RT-PCR) assay [7] with the primers described in Table 2 [8], while primers N1/N2 and N3/N4 were used for detection of virus nucleic acid, and primers N1/N5 and N6/N2 were used for the amplification of full-length $N$ gene (Table 2).

PCR products were purified with the PCR product extraction kit (Omega Bio-Tek, Inc., Norcross, GA, USA), and cloned into the pMD18-T vector with a TA cloning kit (TaKaRa; Dalian, China) following the manufacturers' instructions. Transformed clones were identified by restriction enzyme digestion and subjected to DNA sequencing. To increase the accuracy, we selected three clones of each fragment for sequencing. The sequence of the three clones that exhibited 100\% homology was identified as the target sequence. Sequences were then aligned and compared with the $N$ gene sequences of the reference strains obtained from GenBank using the software Bioedit version 7.0.1 (DNASTAR, Inc.; Madison, WI, USA) and MEGA version 4.0.

\section{Data analysis}

All data were entered into Microsoft Excel 2007 (Microsoft, Inc.; Redmond, WA, USA), and all statistical analyses were performed using the statistical software SPSS version 13.0 (SPSS, Inc.; Chicago, IL, USA). Differences of proportions were tested for statistical significance using chi-square test, and a $P$ value $<0.05$ was considered statistically significant.

\section{Results \\ Epidemiological profile of human rabies cases}

During the period from 2002 to 2012, a total of 226 human rabies cases were reported in Fujian Province, Southeast China. The cases included 147 men and 79 women, and had a mean age of 34.6 years (range, 1 to 88 years). The professions included farmers (138 cases), students (29 cases), workers (22 cases), preschool-aged children (14 cases), housekeepers (13 cases), and unknown (10 cases). The human cases were distributed across Fujian Province, including Quanzhou (85 cases), Longyan (67 cases), Sanming (47 Cases), Nanping (11 cases), Ningde (10 cases), Xiamen (3 cases), Fuzhou (1 case), Pingtan (1 case) and Putian (1 case), and 88.1\% cases were reported in the three cities of Quanzhou, Longyan and Sanming. The annual number of human rabies cases is shown in Fig. 2. 


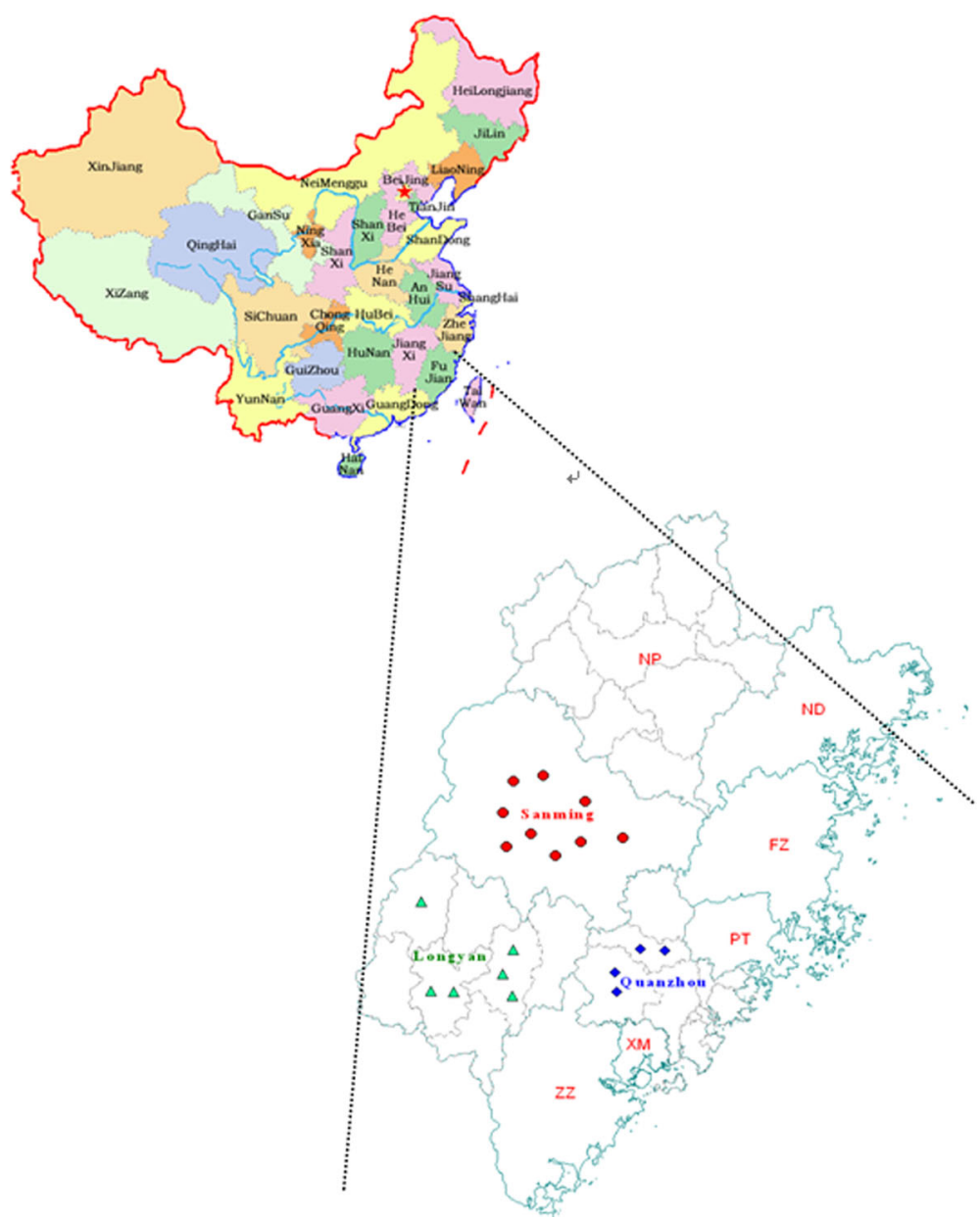

Fig. 1 Geographical distribution of rabies virus isolates in Fujian Province, Southeast China

\section{Rabies virus antigen in canine saliva}

To investigate the incidence of rabies virus antigen in canine populations, a total of eight rabid dogs and 3492 seemingly healthy dogs were randomly selected from 27 villages of Quanzhou, Longyan and Sanming cities, of nine villages in each city, and dog saliva samples were collected. There were six of eight rabid dogs (75\%) with detectable rabies viral antigen, and surprisingly, 165 of 3492 seemingly healthy dogs (4.7\%) were positive for rabies virus antigens in saliva samples, suggesting that a considerable proportion of asymptomatic seemingly healthy dogs carries rabies virus (Fig. 3). There was a statistical significance in the incidence of rabies viral antigen between rabid and seemingly healthy dogs $(P<0.01)$.

\section{$N$ gene fragments in canine brain specimens}

Nested RT-PCR assay detected a 443 bp viral gene fragment in the brain specimens from seven of eight rabid dogs $(87.5 \%)$ and 12 of 81 seemingly healthy dogs (14.8\%), and then, all fragments were amplified with primers N1/N2 and N3/N4. Subsequently, the full- length $N$ gene (1485 bp) was obtained from these positive specimens with primers N1/N5 and N6/N2. The amplicons were cloned into the pMD18-T vector, and subjected to DNA sequencing (GenBank accession numbers: FJ561726-FJ561732, FJ866827-FJ866831 and FJ866834-FJ866836).

\section{Phylogenetic analysis of full-length $\mathbf{N}$ genes}

Putative amino acid sequences of the 19 nucleoproteins were compared with the reference $N$ gene sequence available in GenBank. Based on sequence alignment and phylogenetic tree analysis, these $19 \mathrm{~N}$ genes were characterized as the genotype I rabies virus, although three distinct clusters were found to be geographic regionspecific (Groups A to C) (Fig. 4). Sequencing analyses revealed $99.7 \%$ to $100 \%$ intra-group homology of $N$ genes, and $86.4 \%$ to $89.3 \%$ inter-group homology at a nucleotide level, and $98.9 \%$ to $100 \%$ intra-group homology and $95.3 \%$ to $98.4 \%$ inter-group homology at an amino acid level, respectively. 
Table 1 Geographical origin and time of collection of the 19 dog samples used for amplification of the rabies virus nucleoprotein gene

\begin{tabular}{|c|c|c|c|c|}
\hline $\begin{array}{l}\text { Numbering of } \\
\text { dog samples }\end{array}$ & $\begin{array}{l}\text { Numbering of rabies } \\
\text { virus isolates }\end{array}$ & $\begin{array}{l}\text { Geographical origin of } \\
\text { dog samples }\end{array}$ & Status of dogs & $\begin{array}{l}\text { Time of sample } \\
\text { collection }\end{array}$ \\
\hline LY19 & FJ001 & Longyan & Seemingly healthy dogs & $03 / 2007$ \\
\hline LY36 & FJ002 & Longyan & Seemingly healthy dogs & 03/2007 \\
\hline LY31 & FJ003 & Longyan & Seemingly healthy dogs & 04/2007 \\
\hline QZ27 & FJ004 & Quanzhou & Seemingly healthy dogs & 03/2007 \\
\hline QZ 31 & FJ005 & Quanzhou & Seemingly healthy dogs & 03/2007 \\
\hline QZ 196 & FJ006 & Quanzhou & Seemingly healthy dogs & 03/2007 \\
\hline QZ 260 & FJ007 & Quanzhou & Seemingly healthy dogs & 03/2007 \\
\hline SM9 & FJ008 & Sanming & Rabies suspected dogs & $11 / 2008$ \\
\hline SM10 & FJ009 & Sanming & Rabies suspected dogs & $11 / 2008$ \\
\hline SM11 & FJ010 & Sanming & Rabies suspected dogs & $01 / 2009$ \\
\hline SM12 & FJ011 & Sanming & Rabies suspected dogs & $01 / 2009$ \\
\hline LY47 & FJ012 & Longyan & Seemingly healthy dogs & $04 / 2007$ \\
\hline LY48 & FJ013 & Longyan & Seemingly healthy dogs & 03/2007 \\
\hline LY55 & FJ014 & Longyan & Seemingly healthy dogs & $04 / 2007$ \\
\hline SM2 & FJ015 & Sanming & Seemingly healthy dogs & $11 / 2008$ \\
\hline SM5 & FJ016 & Sanming & Seemingly healthy dogs & $11 / 2008$ \\
\hline SM14 & FJ017 & Sanming & Rabies suspected dogs & 02/2009 \\
\hline SM15 & FJ018 & Sanming & Rabies suspected dogs & 02/2009 \\
\hline SM16 & FJ019 & Sanming & Rabies suspected dogs & 02/2009 \\
\hline
\end{tabular}

\section{Discussion}

Analysis of the 1960-2014 notifiable surveillance data showed that rabies is still a serious public health concern in China, with a total of 120,913 human rabies cases reported in mainland China, including $19.8 \%$ cases observed during the period from 2004 through 2014 [9]. The highest incidence was recorded in 1981 $(0.71 / 100,000)$, and in $2007(0.25 / 100,000)$, and 59\% of total cases were reported from June to November, including $11.0 \%$ of total cases observed in August. In addition, human rabies cases were reported in all provinces of in China, and the eastern and southern regions were more seriously affected relative to other regions [9]. Fujian Province is located in Southeast China, and is a high-risk environment for rabies [10]. The notifiable surveillance data showed 1894 human rabies cases during 1980-1989, 165 human cases during 1990-2000 [11], 206 human cases in 2000-2007
[12], and 123 human cases from 2006 to 2010 [5]. In 2013, only two human rabies cases and two deaths were observed in Fujian Province [13]. These data demonstrates an overall steady decline of human rabies cases in Fujian Province, Southeast China since 1980.

Rabies virus has a single-stranded, antisense, nonsegmented RNA virus genome (approximately $12 \mathrm{~kb}$ ) encoding five viral proteins, including glycoprotein (G), nucleoprotein $(\mathrm{N})$, phosphoprotein $(\mathrm{P})$, matrix protein (M) and polymerase (L) [14]. $N$ gene is highly conserved within the same subtype, and variations in this region can be used for virus subtyping and genotyping [15]. Nucleoprotein can protect viral nucleic acid from being damaged by host cell nuclease [16], and is one of the major protective antigens that induce cell-mediated immunity against rabies virus infection [17]. Molecular characterization of rabies virus $N$ genes has been performed in some provinces of China [18-20]; however,

Table 2 Primers used for nested RT-PCR amplification of the rabies virus nucleoprotein gene

\begin{tabular}{|c|c|c|c|c|c|}
\hline Primer & Sequence $\left(5^{\prime}-3^{\prime}\right)$ & Direction & Positions in genome & Paired primer & $\overline{\text { Product size }(b p)}$ \\
\hline N1 & ACAGACAGCGTCASATTGCAAAGC & Upstream & $29-50$ & N2 & 1511 \\
\hline N2 & TCGGATTGACGAAGATCTTGCTC & Downstream & $1517-1539$ & $\mathrm{~N} 1$ & 1511 \\
\hline N3 & TTTGAGACTGCTCCTTTT & Upstream & $587-605$ & N4 & 443 \\
\hline N4 & CCCATATAGCATCCTAC & Downstream & 1013-1029 & N3 & 443 \\
\hline N5 & CAGTCTCYTCNGCCATCT & Downstream & $1570-1587$ & $\mathrm{~N} 1$ & 1559 \\
\hline N6 & ATGTAACACCTCTACAATGG & Upstream & $55-74$ & N2 & 1485 \\
\hline
\end{tabular}




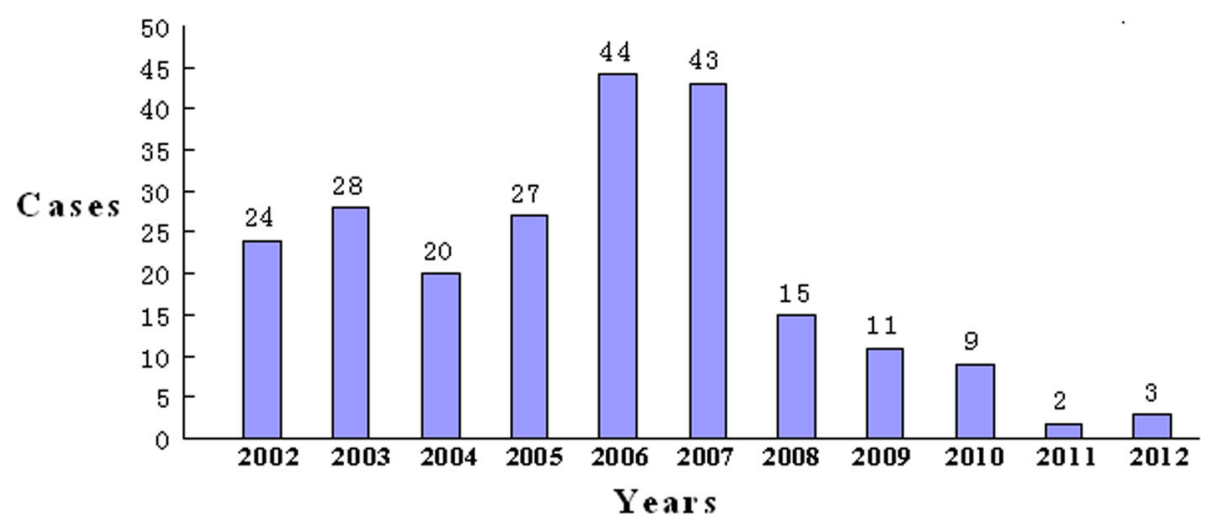

Fig. 2 Annual rabies human cases reported in Fujian Province from 2002 to 2012

the genotypes of dog rabies viruses remain unclear in Fujian Province, Southeast China to date.

This study is the first survey on rabies incidence in domestic dogs in Fujian Province, Southeast China. Saliva specimens, which were collected from rabid and seemingly healthy dogs in 27 villages of Quanzhou, Longyan and Sanming cities, were detected for rabies virus antigen by an ELISA assay, and $4.7 \%$ of seemingly healthy dogs were positive for rabies virus antigens. Then, dogs with ELISA-positive saliva were sacrificed and brain specimens were sampled for the subsequent nested RTPCR assay. Surprisingly, nested RT-PCR assay detected a $443 \mathrm{bp}$ viral $N$ gene fragment in the brain specimens of $14.8 \%(12 / 81)$ of seemingly healthy dogs. The results suggest that there are a considerable proportion of false negatives in preliminary screening by ELISA. Indeed, the reliability, reproducibility and diagnostic value of rabies virus antigen detection remain in debate in canine saliva since the complicated components in saliva specimens may affect ELISA assays, and no standardized kits are available in market until now [21-23]. In addition, virus release occurs at limited intervals in infected dogs, and the difference in sampling time-points may partially contribute to great variations in rabies virus detection among different geographical regions, even inconsistent with local epidemiological conditions.

Sequencing analysis of the 19 full-length $N$ genes revealed over $80 \%$ nucleotide and amino acid homology between rabies viral isolates form Fujian Province and other strains globally. Our findings demonstrate that seemingly healthy dogs may serve as carriers of rabies virus. Although the virus samples were captured from only three cities of the province, a considerable proportion of infected dogs inhabited in the communities without any obvious symptoms for a period of time, which is inconsistent with previous reports [24-26]. Nested RTPCR assay established in this study was found to be more sensitive in detection of rabies in seemingly healthy dogs. The mechanism for infected dogs without illness onset is still unclear; however, seemingly healthy dogs have important values in public health and cannot be neglected.

Canine vaccination has been shown to be the most effective approach for the prevention of human rabies,

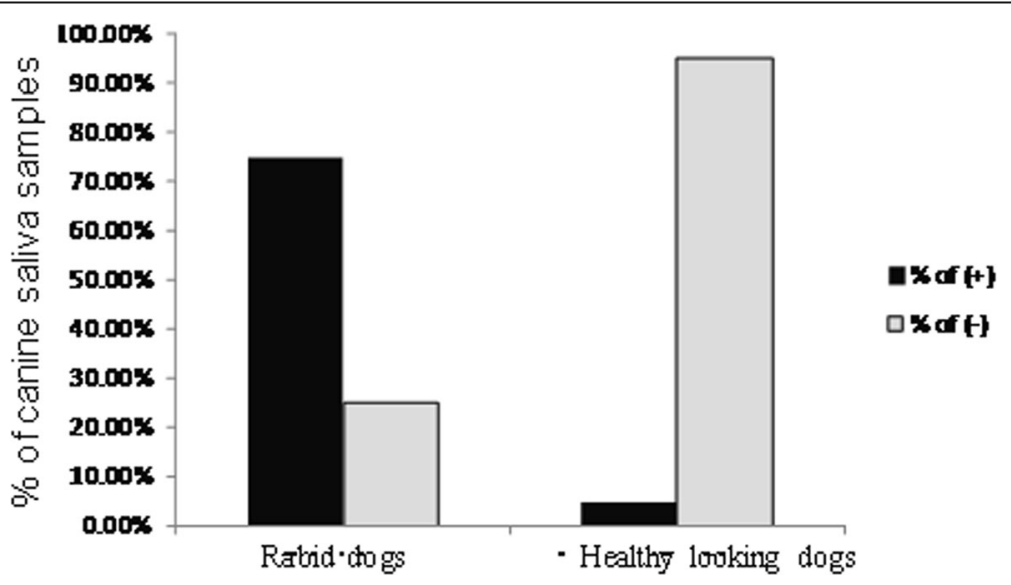

Fig. 3 Detection of rabies virus antigens in rabid and seemingly healthy dogs 


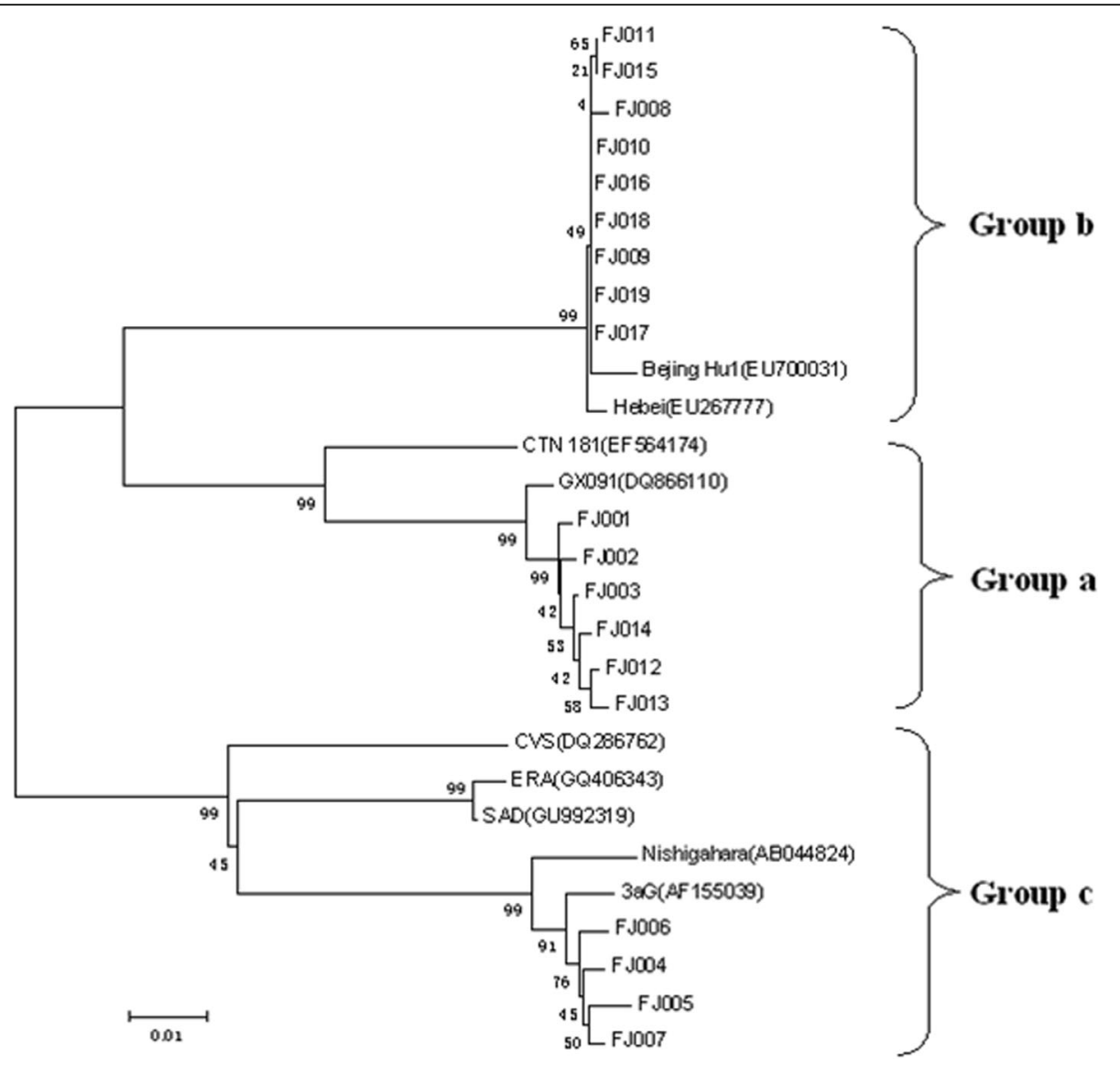

Fig. 4 Phylogenetic analysis of amino acid sequences for rabies virus nucleoprotein. FJ001 to FJ019 rabies virus isolates were identified in this study, while the other sequences were downloaded from GenBank as reference sequences. Three genetically clustered groups were generated

and it is theoretically possible to eliminate cases of the deadly rabies virus in people worldwide through mass canine vaccination [27]. However, the majority of dogs in the developing world are not given vaccination, such as India, China, and Pakistan, which challenges the control efforts and global rabies elimination program [27]. Currently, the most widely used veterinary rabies vaccines include inactivated, attenuated and genetically engineered vaccines in the world $[28,29]$. In China, only veterinary inactivated and attenuated rabies vaccines are available [30]. In this study, most of the dogs were freeranging dogs in rural areas, which did not receive vaccination. It is therefore suggested that, on one hand, rabies virus vaccine inoculation for domestic animals like dogs and cats should be popularized for rabies prevention and control; on other hand, if a dog has no history of definite vaccination, medical personnel should give a standard treatment to dog-bitten outpatients, and vaccinate them according to recommended vaccination protocols, regardless of health status.

To date, there have been seven genotypes of rabies virus characterized [31]. Based on the sequence of the rabies virus $N$ gene, six clearly distinct genotypes were distinguished according to their percentage of amino acid similarity, including the vaccinal and classical rabies viruses of genotype 1, genotypes 2 (Lagos bat virus) and 3 (Mokola virus), genotypes 4 (Duvenhage virus) and 5 (EBL1) and genotype 6 represented by European bat lyssaviruses (EBL) serotype 2 (EBLV-2) [32]. In addition, genotype 7 (Australian bat lyssavirus, ABLV) was isolated from Australian bats [33]. Currently, the majority of the rabies viruses isolated from human cases were characterized as genotype 1 [30]. In the present study, sequencing analysis revealed that the 19 full-length rabies virus $N$ genes belonged to genotype I. According to their geographical origins, three distinct clusters (groups A, B, and C) were originated exclusively from western, northern and southern Fujian, respectively, which is in agreement with previous studies [34-36]. Phylogenetic analysis showed that the viral isolates in Group A shared the highest homology with a Guangxi isolate GX091, while viral isolates in Group B shared the highest homology with a Beijing isolate (Beijing Hu1). Notably, the viral isolates in Group $C$ shared the highest homology with a vaccine strain $3 \mathrm{aG}$ and Nishigahara, a Japanese strain of veterinary vaccine. As a southeast 
coastal province of China, the complexity of rabies virus distribution in Fujian may reflect its geographic location with rapid economic development and frequent international communications. However, the detailed routes for rabies virus transmission cannot be determined among different cities to date, since limited molecular evidence is available in Fujian and neighboring regions.

The present study has several limitations. First, ELISA-positive saliva samples were not confirmed by RT-PCR. Our nested RT-PCR, which was employed to detect viral $N$ gene in the brain specimens of dogs with ELISA-positive saliva samples, showed the low sensitivity (14.8\%) of ELISA for the detection of rabies virus antigens in canine saliva specimens. As described above, ELISA detection is affected by multiple factors. Fortunately, the phylogenetic analysis is not affected, since the full-length $\mathrm{N}$ gene was amplified from PCR-positive samples. Second, we did not observe the dogs with ELISA-positive saliva samples for a period of time to see the eventual development of rabies or not. Third, we did not detect $G$ gene in the canine samples. Currently, the rabies virus vaccine strains are CTN, $3 \mathrm{aG}, \mathrm{PV}$ and Flury in Fujian province, and veterinary vaccine strains are ERA and SAD. Since G protein is the major inducer of protective immunity against rabies [37], we cannot link our findings with the rabies vaccination in Fujian Province.

\section{Conclusions}

This is the first description pertaining to the epidemiological characteristics of human rabies cases and characterization of the rabies virus $N$ gene in dogs in Fujian Province, Southeast China. Our findings may provide valuable knowledge for the development of strategies targeting the prevention and control of rabies. Further extensive surveillance is required to track virus evolution, and infection status in dogs and other carrier species.

\section{Abbreviations}

CDC: Center for Disease Control and Prevention; ELISA: Enzyme-linked immunosorbent assay; G protein: Glycoprotein; L protein: Polymerase; M protein: Matrix protein; N protein: Nucleoprotein protein; P

protein: Phosphoprotein; RT-PCR: Reverse transcription polymerase chain reaction

\section{Acknowledgements}

We would like to thank the staff from the Department of Natural Foci Diseases, Fujian Provincial Center for Disease Control and Prevention for their kind participation in the field work. Many thanks are addressed to Dr. Yu-Ping Wang from Fujian International Travel Healthcare Center for his kind help during data collection and writing of the manuscript.

\section{Funding}

This study was supported by the grants from the Natural Science Foundation of Fujian Province (grant nos. 2012 J05133 and 2015 J01152), Fujian Provincial Medical Innovation Projects (grant no. 2007-CX-5) and Jiangsu Provincial Medical Youth Talent, the Project of Invigorating Health Care through Science, Technology and Education (grant no. QNRC2016621). The funders had no role in the study design, data collection and analysis, decision to publish, or preparation of the manuscript
Availability of data and materials

All data described in the study can be provided for free by contact with the corresponding author.

\section{Authors' contributions}

YSY conceived and designed the study. JMZ, ZSZ, YQD, SLW and WW performed the field experiments. JMZ, ZSZ, YQD and SLW collected and analyzed the data. $J M Z$ and ZSZ prepared the first version of the manuscript. YQD, SLW and YSY critically reviewed the manuscript. WW revised and finalized the manuscript. All authors read and approved the final version of the manuscript.

\section{Ethics approval}

This study was approved by the Ethical Review Committee of Fujian Provincial Center for Disease Control and Prevention (permission number: FJCDC-001207), and the study protocol was reviewed by the Institutional Review Board of Fujian Provincial Center for Disease Control and Prevention. All animal experiments were performed according to the Guidelines for the Care and Use of Laboratory Animals, and written informed consent was obtained from all human rabies cases described in this study.

\section{Consent for publication}

Not applicable.

\section{Competing interests}

The authors declare that they have no competing interests.

\section{Publisher's Note}

Springer Nature remains neutral with regard to jurisdictional claims in published maps and institutional affiliations.

\section{Author details}

${ }^{1}$ Clinical Laboratory, The Affiliated Quanzhou First Hospital of Fujian Medical University, No. 248 East Street, Quanzhou City, Fujian Province 362002, China. ${ }^{2}$ School of Public Health, Fujian Medical University, Fuzhou City, Fujian Province 350004, China. ${ }^{3}$ Fujian Provincial Center for Disease Control and Prevention, Fuzhou City, Fujian Province 350001, China. ${ }^{4}$ Fujian Provincial Key Laboratory of Zoonosis Research, Fuzhou City, Fujian Province 350001, China. ${ }^{5}$ Jiangsu Institute of Parasitic Diseases, No. 117 Yangxiang, Meiyuan, Wuxi City, Jiangsu Province 214064, China. ${ }^{6}$ Key Laboratory of National Health and Family Planning Commission on Parasitic Disease Control and Prevention, Wuxi City, Jiangsu Province 214064, China. ${ }^{7}$ Jiangsu Provincial Key Laboratory on Parasites and Vector Control Technology, Wuxi City, Jiangsu Province 214064, China.

Received: 28 April 2017 Accepted: 22 August 2017

Published online: 30 August 2017

References

1. Zinsstag J. Towards a science of rabies elimination. Infect Dis Poverty. 2013;2:22.

2. Yin W, Dong J, Tu C, Edwards J, Guo F, Zhou H, Yu H, Vong S, Rabies Technical and Advisory Board. Challenges and needs for China to eliminate rabies. Infect Dis Poverty. 2013;2:23.

3. Yu J, Li H, Tang Q, Rayner S, Han N, Guo Z, Liu H, Adams J, Fang W, Tao X, Wang S, Liang G. The spatial and temporal dynamics of rabies in China. PLoS Negl Trop Dis. 2012;6:e1640.

4. Xie ZH, Huang WL, Hong RT, Li H, Xiang JJ. Analysis of the epidemiological trends of human rabies in Fujian province, 2004-2007. Dis Surveill. 2009:24:37-9.

5. Xiao FZ, Deng YQ, Chen L, Wang LL. Epidemiological characteristics of rabies in Fujian Province, 2006-2010. Chin J Dis Control Prev. 2012:16:917-8.

6. Chen J, Zou L, Jin Z, Ruan S. Modeling the geographic spread of rabies in China. PLoS Negl Trop Dis. 2015;9:e0003772.

7. Picard-Meyer E, Bruyère V, Barrat J, Tissot E, Barrat MJ, Cliquet F. Development of a hemi-nested RT-PCR method for the specific determination of European Bat Lyssavirus 1. Comparison with other rabies diagnostic methods. Vaccine. 2004;22:1921-9.

8. Liu Q, Xiong Y, Luo TR, Wei YC, Nan SJ, Liu F, Pan Y, Feng L, Zhu W, Liu K, Guo JG, Li HM. Molecular epidemiology of rabies in Guangxi Province, south of China. J Clin Virol. 2007:39:295-303.

9. Zhou H, Vong S, Liu K, Li Y, Mu D, Wang L, Yin W, Yu H. Human rabies in China, 1960-2014: a descriptive epidemiological study. PLoS Negl Trop Dis. 2016;10:e0004874. 
10. Wu X, Hu R, Zhang Y, Dong G, Rupprecht CE. Reemerging rabies and lack of systemic surveillance in People's Republic of China. Emerg Infect Dis. 2009; 15(8):1159-64

11. Chen Y, Liu JM, Jiang AM. Rabies epidemics and surveillance in Fujian Province during the latest 20 years. Strait J Prev Med. 2002;8:36-7.

12. Wang LL. Rabies epidemics and control in Fujian Province from 2000 to 2007. Strait J Prev Med. 2009;15:29-31.

13. Xiao FZ, Deng YQ, Chen L, Wang LL. Analysis on surveillance of human rabies, Fujian Province, 2013. Prev Med Trib. 2015;21:694-6.

14. Rupprecht C, Hanlon CA, Hemachudha T. Rabies re-examined. Lancet Infect Dis. 2002;2:327-43.

15. Tordo N, Poch O, Ermine A, Keith G. Primary structure of leader RNA and nucleoprotein genes of the rabies genome: segmented homology with VSV. Nucleic Acids Res. 1986;6:2671-283

16. Liu P, Yang J, Wu X, Fu ZF. Interactions amongst rabies virus nucleoprotein phosphoprotein and genomic RNA in virus infected and transfected cells. J Gen Virol. 2004;12:3725-34.

17. Goto H, Minamoto N, Ito H, Ito N, Sugiyama M, Kinjo T, Kawai A. Mapping of epitopes and structural analysis of antigenic sites in the nucleoprotein of rabies virus. J Gen Virol. 2006;81:119-27.

18. Meng SL, Yan JX, Xu GL, Nadin-Davis SA, Ming PG, Liu SY, Wu J, Ming HT, Zhu FC, Zhou DJ, Xiao QY, Dong GM, Yang XM. A molecular epidemiological study targeting the glycoprotein gene of rabies virus isolates from China. Virus Res. 2006;124:125-38.

19. Zhang HL, Zhang YZ, Yang WH, Tao XY, Li H, Ding JC, Feng Y, Yang DJ, Zhang J, He J, Shen XX, Wang LH, Zhang YZ, Song M, Tang Q. Molecular epidemiology of reemergent rabies in Yunnan Province, southwestern China. Emerg Infect Dis. 2014;20:1433-42.

20. Tao XY, Tang Q, Li H, Mo ZJ, Zhang H, Wang DM, Zhang Q, Song M, Velasco-Villa A, Wu X, Rupprecht CE, Liang GD. Molecular epidemiology of rabies in Southern People's Republic of China. Emerg Infect Dis. 2009;15: 1192-8.

21. Wang YJ, Qi FC, Xue XG, Li XB, Wang LN, Xie L, Wang Y, Xia QJ, Sui B, Zhang M, Wei T, Guo LJ. Development and application of ELISA method for rabies virus antigen. Chin J Biol. 2009;22:713-5.

22. Woldehiwet Z. Clinical laboratory advances in the detection of rabies virus. Clin Chim Acta. 2005;351:49-63.

23. Moore SM, Hanlon CA. Rabies-specific antibodies: measuring surrogates of protection against a fatal disease. PLoS Negl Trop Dis. 2010;4:e595.

24. Fekadu M, Shaddock JH, Chandler FW, Baer GM. Rabies virus in the tonsils of a carrier dog. Arch Virol. 1983;78:37-47.

25. Kikkawa A, Uchida Y, Suwa Y, Taguchi K. A novel method for estimating the adaptive ability of guide dogs using salivary slgA. J Vet Med Sci. 2005;67:707-12.

26. Zhang YZ, Fu ZF, Wang DM, Zhou JZ, Wang ZX, Lv TF, Xiong CL, Zou Y, Yao WR, Li MH, Dong GM, Xu GL, Niezgoda M, Kuzmin IV, Rupprecht CE. Investigation of the role of healthy dogs as potential carriers of rabies virus. Vector Borne Zoonotic Dis. 2008:8:313-9.

27. Davlin SL, Vonville HM. Canine rabies vaccination and domestic dog population characteristics in the developing world: a systematic review. Vaccine. 2012;30:3492-502.

28. Frana TS, Clough NE, Gatewood DM, Rupprecht CE. Postmarketing surveillance of rabies vaccines for dogs to evaluate safety and efficacy. J Am Vet Med Assoc. 2008;232:1000-2.

29. Lewis CE, Fry AM, Hermann JR, Siev D, Dusek DM, Gatewood DM. Potency testing of veterinary rabies vaccines: replacement of challenge by in vitro testing: considerations for development of alternative assays. Dev Biol (Basel). 2012;134:29-33.

30. Zhu WY, Liang GD. Current status of canine rabies in China. Biomed Environ Sci. 2012;25:602-5.

31. Singh R, Singh KP, Cherian S, Saminathan M, Kapoor S, Manjunatha Reddy GB, Panda S, Dhama K. Rabies - epidemiology, pathogenesis, public health concerns and advances in diagnosis and control: a comprehensive review. Vet Q. 2017;37:212-51

32. Bourhy H, Kissi B, Tordo N. Molecular diversity of the Lyssavirus genus. Virology. 1993;194:70-81

33. Speare R, Skerratt L, Foster R, Berger L, Hooper P, Lunt R, Blair D, Hansman $D$, Goulet $M$, Cooper $S$. Australian bat lyssavirus infection in three fruit bats from north Queensland. Commun Dis Intell. 1997:21:117-20.

34. von Teichman BF, Thomson GR, Meredith CD, Nel LH. Molecular epidemiology of rabies virus in South Africa: evidence for two distinct virus groups. J Gen Virol. 1995;76:73-82.
35. Yang DK, Shin EK, Oh YI, Kang HK, Lee KW, Cho SD, Song JY. Molecular epidemiology of rabies virus circulating in South Korea, 1998-2010. J Vet Med Sci. 2011;73:1077-82.

36. Song M, Tang Q, Wang DM, Mo ZJ, Guo SH, Li H, Tao XY, Rupprecht CE, Feng ZJ, Liang GD. Epidemiological investigations of human rabies in China. BMC Infect Dis. 2009;9:210.

37. Dietzschold B, Wang HH, Rupprecht CE, Celis E, Tollis M, Ertl H, Heber-Katz E, Koprowski $\mathrm{H}$. Induction of protective immunity against rabies by immunization with rabies virus ribonucleoprotein. Proc Natl Acad Sci U S A. 1987;84:9165-9

\section{Submit your next manuscript to BioMed Central and we will help you at every step:}

- We accept pre-submission inquiries

- Our selector tool helps you to find the most relevant journal

- We provide round the clock customer support

- Convenient online submission

- Thorough peer review

- Inclusion in PubMed and all major indexing services

- Maximum visibility for your research

Submit your manuscript at www.biomedcentral.com/submit
Biomed Central 